\title{
Biginelli vs Hantzsch esters study under infrared radiation and solventless conditions
}

\author{
Roberto Osnaya, ${ }^{\text {a }}$ Gabriel A. Arroyo, ${ }^{\text {a Luis Parada, }}$ ' Francisco Delgado, \\ José Trujillo, ${ }^{\mathrm{d}}$ Manuel Salmón, ${ }^{\mathrm{e}}$ and René Miranda ${ }^{\mathrm{a}^{*}}$ \\ ${ }^{a}$ Facultad de Estudios Superiores Cuautitlán Campo 1, Universidad Nacional Autónoma de \\ México, Av. 1ro de Mayo s/n, Colonia Santa María las Torres, Cuautitlán Izcalli, Estado de \\ México, México, C.P. 54740 \\ ${ }^{b}$ Escuela de Química Universidad de El Salvador, Final 25 Avenida Norte, Ciudad \\ Universitaria, San Salvador \\ ${ }^{c}$ Escuela Nacional de Ciencia Biológicas, Instituto Politécnico Nacional, Prolongación Carpio \\ y Plan de Ayala, Casco de Santo Tomás, México D.F., C.P. 11340 \\ ${ }^{d}$ Escuela Superior de Medicina, Instituto Politécnico Nacional, Plan de San Luis y Díaz Mirón, \\ México D.F., C.P. 11340 \\ e Instituto de Química, Universidad Nacional Autónoma de México, Circuito Exterior, Ciudad \\ Universitaria, México, D. F., CP 04510 \\ E-mail:mirruv@latinmail.com
}

(received 18 Jul 03; accepted 20 Nov 03; published on the web 25 Nov 03)

\begin{abstract}
In this work, we report the results obtained during the condensation of various benzaldehydes with ethyl acetoacetate and urea or thiourea, in the presence of a bentonitic clay as catalyst. These reactions were performed under solventless conditions with infrared radiation as the energy source. Both Biginelli and Hantzsch esters were synthesized, with the Biginelli compounds being the main products. Finally, the obtained compounds were characterized by comparison of the corresponding melting points with those reported in the literature, together with the EIMS data and the elemental composition obtained by high resolution MS.
\end{abstract}

Keywords: Biginelli, Hantzsch, solventless, infrared radiation, bentonitic clay

\section{Introduction}

It is well known in the protocol of green chemistry that its main objective is to perform reactions under solventless conditions using heterogeneous catalysts, in order to generate eco-friendly chemical transformations. ${ }^{1}$ In addition, it is important to note that an ideal synthesis has been 
established as one in which a target molecule is produced quantitatively in one step, from available and inexpensive raw materials, under environmentally harmless processes. ${ }^{2}$

The one-pot acid-catalyzed Biginelli condensation ${ }^{3}$ is the most commonly used reaction to produce dihydropyrimidines (DHPMs); this very simple method involves three component condensation of (thio)ureas, aldehydes and $\beta$-oxoesters or 1,3-dicarbonyl compounds, using ethanol as the solvent, and catalytic amounts of $\mathrm{HCl}, \mathrm{AcOH}$ or $\mathrm{H}_{2} \mathrm{SO}_{4}$ among others acids. ${ }^{4-6}$ In this way are obtained with low to moderate yields the desired molecules. ${ }^{7-9}$ Also, some other improved reactions have been performed for the synthesis of DHPMs, either by modification of the classical one-pot Biginelli or by means of complex multistep strategies. ${ }^{10}$ On the other hand, the Hantzsch reaction, discussed more than 120 years ago, ${ }^{11}$ the main way to obtain dihydropyridines (DHPs), is also commonly carried out as a one-pot condensation of $\beta$ dicarbonyl compounds with aldehydes but with ammonia, using ethanol as the solvent under reflux. Furthermore, in relation to the previously mentioned protocols, it is worth noting that few papers have informed that the Hantzsch type molecules may be side products under standard Biginelli conditions. ${ }^{12-16}$ These two classes of molecules represent heterocyclic systems of remarkable pharmacological activity. For example, a broad number of biological effects, including antiviral, antitumor, antibacterial, and anti-inflammatory activities, have been ascribed to them. ${ }^{17}$ Moreover, some of these heterocyclic compounds have emerged as orally active antihypertensive agents or $\alpha-1 \mathrm{~A}$-adrenoceptor-selective antagonists. ${ }^{18}$

It is also appropriate to mention, that the revision of fundamental synthetic reactions under heterogeneous catalysis, using TAFF a commercial bentonitic clay, ${ }^{19}$ represents the main subject of our research group. ${ }^{20}$ Thus, the aim of this paper is to highlight a competition between the Biginelli and the Hantzsch reactions in the presence of TAFF (Scheme 1), using infrared radiation as the energy source without solvent. In this sense, a contribution to the greenchemistry protocol is offered.

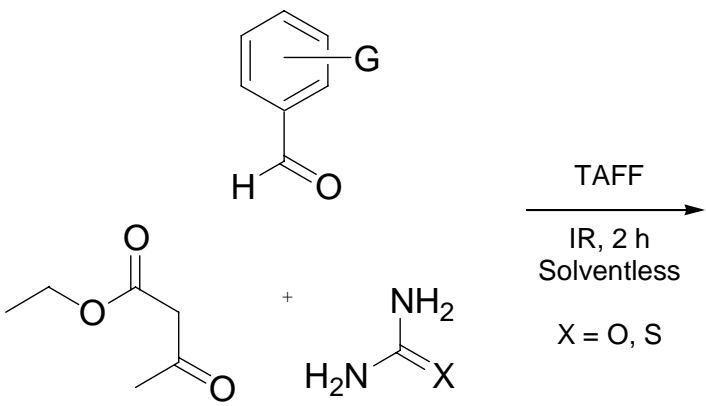

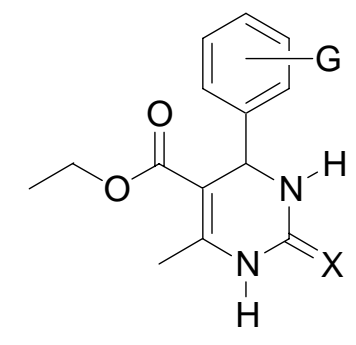

1-8

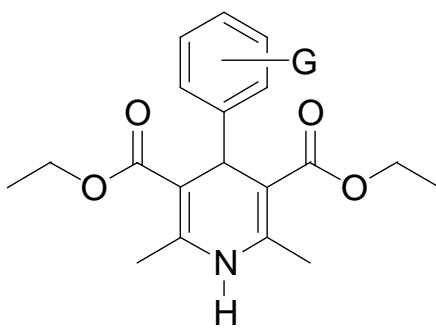

9-12

\section{Scheme 1}

\section{Results and Discussion}


In Table 1, various results of the performed experiments have been summarized. As it can be observed, both DHPMs 1-8 and the corresponding DHPs 9-12 were obtained. In general, the molecules 1-8 were the main products. It is worth noting, that our initial attempts were focused on the use of neat TAFF as the reaction mediator (i.e. solvent). Although the yields of crude dihydropyrimidone were suitable ( $c$ a $50 \%$ ), a side-reaction leading to an unwanted by-product (Hantzsch) was carried out simultaneously.

After varying the experimental conditions in terms of the molar ratio of reactants, temperature, time and quantities of the catalyst, we found a set of conditions that consistently produced the best yields of dihydropyrimidones 1-8. The presence of TAFF as the reaction mediator (150 mg, per $8 \mathrm{mmol}$ of reactants) provided the highest yields and lower time of reaction ( $2 \mathrm{~h}$ ), as encountered by a simple optimization study. Once the reaction was completed, the mixture was purified by chromatography. In all the studied cases, the TAFF/irradiation method produced competitive yields of DHPMs (45-62 \%) in comparison to the classical Biginelli procedure (vide supra). Therefore, the formation of 1-8 can be explained only by the reaction of benzaldehyde with one of the early intermediates in the Biginelli condensation process. ${ }^{21}$ No attempts were made to clarify this point. Moreover, 9-12 were probably promoted by the ammonia produced by decomposition of urea (thiourea).

Table 1. Competitive formation of Biginelli and Hantzsch Esters, under infrared radiation, solventless conditions and presence of TAFF

\begin{tabular}{|c|c|c|c|c|c|c|c|c|c|c|}
\hline \multirow[b]{3}{*}{ G / X } & \multicolumn{3}{|c|}{ DHPMs } & & & \multicolumn{4}{|c|}{ DHPs } & \\
\hline & & & & \multicolumn{2}{|l|}{$\mathrm{m} / \mathrm{z}(\%)$} & & \multirow[b]{2}{*}{$m p^{\mathbf{a}, \mathbf{b}}$} & \multirow[b]{2}{*}{ Yield $^{\mathrm{c}}$} & \multicolumn{2}{|c|}{$\mathrm{m} / \mathrm{z}(\%)$} \\
\hline & & $\mathrm{mp}^{\mathbf{a}, \mathbf{b}}$ & Yield $^{\mathrm{C}}$ & $\mathrm{M}^{+\bullet \cdot}$ & {$[\mathrm{M}-\mathrm{R}]^{+}$} & & & & $\mathrm{M}^{+\bullet}$ & {$[\mathrm{M}-\mathrm{R}]^{+}$} \\
\hline $\mathrm{H} / \mathrm{O}$ & 1 & 206-207 & 55 & $260(75)$ & $183(100)$ & 9 & $156-157$ & 11 & $329(44)$ & $252(100)$ \\
\hline $\mathrm{H} / \mathrm{S}$ & 2 & 208-209 & 45 & 276 (73) & 199 (100) & 9 & $157-159$ & 09 & $329(44)$ & $252(100)$ \\
\hline$p-\mathrm{CH}_{3} / \mathrm{O}$ & 3 & 203-204 & 50 & $274(45)$ & $183(100)$ & 10 & $130-132$ & 08 & 343 (12) & $252(100)$ \\
\hline$p-\mathrm{CH}_{3} / \mathrm{S}$ & 4 & $195-197$ & 53 & $286(41)$ & $199(100)$ & 10 & $131-133$ & 06 & 343 (12) & $252(100)$ \\
\hline$p-\mathrm{CH}_{3} \mathrm{O} / \mathrm{O}$ & 5 & 202-204 & 62 & $290(35)$ & $183(100)$ & 11 & $152-154$ & 11 & 359 (17) & $252(100)$ \\
\hline$p-\mathrm{CH}_{3} \mathrm{O} / \mathrm{S}$ & 6 & $152-153$ & 58 & 306 (43) & 199 (100) & 11 & $151-152$ & 10 & 359 (17) & 252 (100) \\
\hline$o-\mathrm{Cl} / \mathrm{O}$ & 7 & $214-215$ & 60 & 294 (22) & $183(100)$ & 12 & $122-123$ & 11 & 363 (10) & 252 (100) \\
\hline$o-\mathrm{Cl} / \mathrm{S}$ & 8 & $185-187$ & 50 & $310(75)$ & $199(100)$ & 12 & $122-123$ & 08 & $363(10)$ & $252(100)$ \\
\hline
\end{tabular}

${ }^{\mathbf{a}}$ Experimental $\left({ }^{\circ} \mathrm{C}\right) .{ }^{\mathbf{b}}$ Lit-(refs $\left.21-23\right) ;{ }^{\mathbf{c}}$ of isolated pure products (\%).

This technique offers an easy method for the preparation of both classes of molecules. In addition, it provided a particular eco-advantage since it was carried out employing TAFF, as catalyst in the absence of solvent. These results demonstrate that infrared irradiation is a valuable means for the activation of organic compounds. Moreover, the lack of organic solvents along with the use of a bentonitic clay as reaction mediator is a topic of great concern for the environment. Thus, the use of TAFF, as well as solventless conditions in cyclization reactions, is 
currently underway in our laboratories and will be reported in due course. Finally, the products 1-12, were identified by physical and spectral correlation (EIMS and HRMS), i.e. all the molecular ions (Table 1) as well as their corresponding exact mass data, together with the elemental composition, were in agreement with the structure of a Biginelli or a Hantzsch esters, in addition to the general presence of a very abundant fragment $[\mathrm{M}-\mathrm{R}]^{+}$in the MS spectra of both classes of molecules.

\section{Experimental Section}

General Procedures. The aldehydes were purchased from Aldrich Chemical Co. and were employed without further purification. All the reactions were monitored by tlc ( $n$-hexane-AcOEt, 9:1), performed on precoated $(0.25 \mathrm{~mm})$ Merck silica-gel $60-\mathrm{G}_{254}$ aluminum sheets. The product visualization was carried out using a 254 and $365 \mathrm{~nm}$ UV lamp. Melting points were not corrected and were determined on a Fischer-Johns apparatus. The EIMS and the HRMS data were obtained using a JEOL (Peabody, MA, USA) JMS-SX 102 and a JEOL JMS AX 505 HA spectrometers. Polyethylene glycol $(400,800,1000)$ was used as internal reference in the highresolution studies. The limits of the mass measurement were set so in order to cover the last two standard peaks which encompassed the sample peak. The mass resolution and scanning speed used were 10,000 and $120 \mathrm{~s} /$ decade respectively. The accurate mass was given as the mean value of the masses observed after 5-10 scans of mass-spectra and determined from the mass centroids of $[\mathrm{M}+\mathrm{H}]^{+}$peaks. Elemental compositions were calculated within an error of $10 \mathrm{ppb}$ by using the program installed in the system.

General preparative procedure. A mixture of aldehyde, urea (thiourea) and ethyl acetoacetate (8.226 mmol of each one) and $150 \mathrm{mg}$ of activated TAFF were placed in a round-bottomed flask $(50 \mathrm{~mL})$ equipped with a condenser. It was irradiated, by means of an infrared lamp (Osram, 250 watts, 125 volts), ${ }^{24}$ and monitored by tlc for $2 \mathrm{~h}$. After cooling, the reaction mixture was directly purified by chromatography $\left(\mathrm{SiO}_{2} / n\right.$-hexane-AcOEt, 9:1). Finally, 1-12 were identified by comparison of their corresponding melting points in addition to their mass spectra data.

\section{Acknowledgements}

The authors, wish to thank the Dirección General de Asuntos del Personal Académico de la Universidad Nacional Autónoma de México (DGAPA-UNAM) PAPIIT grant IN 208202 for financial support. We thank Gabriela Salcedo and Ma. Concepción Gómez Cervantes for technical assistance 


\section{References and Notes}

1. Anastas, P. T.; Williamson, T. C. Green Chemistry, Frontiers in Benign Chemical Syntheses and Processes, Oxford University Press, 1998.

2. Wender, P. A.; Handy, S. L.; Wright, D. L. Chem. Ind. 1997, 765.

3. (a) Biginelli, P. Gazz. Chim. Ital. 1893, 23, 360. (b) Kappe, C. O. Tetrahedron 1993, 49, 6937.

4. (a) Folkers, K.; Harwood, H. J.; Johnson, T. B. J. Am. Chem. Soc. 1932, 54, 3751.(b) Folkers, K.; Johnson, T. B. J. Am. Chem. Soc. 1933, 55, 3784.

5. Dandia, A.; Saha, M.; Taneja, H. J. Fluorine Chem. 1998, 90, 17.

6. (a) Lu, J.; Bai, Y.; Wang, Z.; Yang, B.; Ma, H. Tetrahedron Lett. 2000, 41, 9075. (b) Kumar, K. A.; Kasthuraiah, M.; Reddy, C. S.; Reddy, C. D.; Tetrahedron Lett. 2001, 42, 7873.

7. O’Reilly, B. C.; Atwal, K. S. Heterocycles 1987, 26, 1185.

8. Atwal, K. S.; O’Reilly, B. C.; Gougoutas, K. S.; Malley, M. F. Heterocycles 1987, 26, 1189.

9. Bussolari, J. C.; McDonnell, P. A. J. Org. Chem. 2000, 65, 6777.

10. (a) Wipf, P.; Cunningham, A. Tetrahedron Lett. 1995, 36, 7819. (b) Studer, A.; Jeger, P.; Wipf, P.; Curran D. P. J. Org. Chem. 1997, 62, 2917. (c) Kappe, C. O. Bioorg. \& Med. Chem. Lett. 2000, 10, 49. (d) Vanden, J. J.; Watté, O. Arkivoc 2003, iv, 93.

11. Hantzsch, A. Just. Leib. Ann. Chem. 1882, 215, 1.

12. Hinkel, L. E.; Hey, D. H. Rec. Trav. Chim. 1929, 48, 1280.

13. Bakibaev, A. A.; Filimonov, V.D. Zhur. Org. Khim. 1991, 27, 854.

14. Bakibaev, A. A.; Filimonov, V. D. Zhur. Org. Khim. 1991, 27, 859.

15. Yadav, J. S.; Subba, B. V.; Thirupathi, P. Synth. Commun. 2001, 31, 425.

16. Tu, S. J.; Zhou, J. F. , Cai, P. J.; Wang, H.; Feng, J. C. Synth. Commun. 2002, 32, 147.

17. Kappe, C. O. Eur. J. Med. Chem. 1991, 34, 1043.

18. Murali, T. G.; Nagarathnam, D.; Marzabadi, M. R.; Lagu, B.; Wong, W. C.; Chiu, G.; Tyagarajan, S.; Wu, S.; Zhang, F.; Sun, W.; Tian, D.; Shen, Q.; Zhang, J.; Wetzel, J. M.; Forray, C.; Chang, R. S. L.; Broten, T. P.; Schorn, T. W.; Bao, T.; O’Malley, S.; Ransom, R.; Schneck, K.; Bendesky, R.; Harrell, C. M.; Vyas, K. P.; Zhang, K. Z.; Gilbert, J.; Pettibone, D. J.; Patane, M. A.; Bock, M. G.; Freidinger, R. M.; Gluchowski, C. J. Med. Chem. 1999, 42, 4778.

19. Tonsil Actisil FF (TAFF), a commercial Mexican bentonitic clay, is available from Tonsil Mexiana S.A. de C.V. Mexico City, at US \$1.30/kg. Examined with X-ray fluorescence, this clay proved to have the following composition (in percent): $\mathrm{SiO}_{2}, 74.5 ; \mathrm{Al}_{2} \mathrm{O}_{3}, 9.3$; $\mathrm{MgO}$, 0.4; $\mathrm{Fe}_{2} \mathrm{O}_{3}, 1.3 ; \mathrm{CaO}, 4.0 ; \mathrm{K}_{2} \mathrm{O}, 0.4 ; \mathrm{TiO}_{2}, 0.4 ; \mathrm{H}_{2} \mathrm{O}$, 9.7. When X-ray thermo diffractograms were run, the laminar structure was found to be unstable above $150^{\circ} \mathrm{C}$. Quartz and cristobalite are important components in the clay composition as observed by Xdiffraction powder. The corresponding BET surface area is $198.718 \mathrm{~m}^{2} \mathrm{~g}^{-1}$ and the pore volume and average pore diameter is $32.04 \times 10^{-2} \mathrm{~cm}^{3} \mathrm{~g}^{-1}$ and $77.8 \AA$, respectively. It is 
worth noting that a detailed characterization of this clay was recently published $\left({ }^{20} \mathrm{Si}\right.$ and ${ }^{27}$ Al MAS-NMR, SEM, IR-Py, DTA and TG). Miranda, R.; Rios, H.; Salmón, M.; Cogordán, J. A.; Castro, M.; Delgado, F. Appl. Cat. A: General 2003, 244, 217.

20. Heterocyclic Preparative Chemistry; 1980 To 2003, Miranda, R.; Arroyo, G.A.; Penieres, G.; Salmón, M.; Cabrera, A.; Álvarez, C.; Delgado; F. Research Trends 2003, in press.

21. Kappe, C. O. J. Org. Chem. 1997, 62, 7201.

22. (a) Hu, E. H.; Sidler, D. R.; Dolling, U. H. J. Org. Chem. 1998, 63, 3454. (b) Wang, L.; Qian, C.; Tian, H.; Ma, Y. Synth. Commun. 2003, 33, 1459. (c) Salehi, P.; Dabiri, M.; Zolfigol, M. A.; Bodaghi, M. A. Tetrahedron Lett. 2003, 44, 2889.

23. (a) Loev, B. J. Med. Chem. 1974, 17, 956. (b)Vigante, B. Khimiya Geterotsiklisheskikh Soedinenii 1982, 2, 219. (c) Watanabe, Y. Synthesis 1983, 9, 761. (d) Singh, H. Heterocycles 1986, 24, 3039.

24. Pool, G. C.; Teuben, J. H. IR Radiation as a Heat Source in Vacuum Sublimation, in: Practical Organometallic Chemistry; Wayda A. L.; Darensbourg M. Y., Eds; Washington D. C. 1987. 